\title{
Exploring The Development Of Student Self-Esteem And Resilience In Urban Schools
}

Imani Akin, University of Phoenix, USA

Leondra Radford, University of Phoenix, USA

\begin{abstract}
This brief study serves as an introduction into exploring the existence of resilience and self-esteem in urban high school learning environments. Data collection stems from interviews and surveys of graduates of urban high schools, who transitioned into college or careers. Findings from this qualitative phenomenological research contains participant recommendations to the specific actions of educators, as well as ideas, lor appropriate learning environments, to foster the resilience and self-esteem which contributes to student academic and social success, leading to adult personal and profession success. Implications of this research include the significance of consideration of the impact of teacher behaviors on student academic and social emotional success within the classrooms of urban schools.
\end{abstract}

Keywords: Resilience; Self-Esteem; Student-Teacher Relationships; Urban Schools

\section{INTRODUCTION}

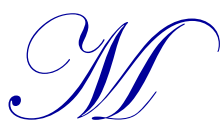

ental health accounts for many of the disparities among the youth within the United States (Merianos, Nabots, Vidourek, \& King, 2013). The disparities may penetrate and affect the teaching and learning which occurs in the classroom. Students who live in and attend schools in urban settings experience multiple disparities, which may contribute to an at-risk status. Educators can create positive learning environments, to build and support student self-esteem, resilience which contribute to positive mental health and student academic and social success.

Learning occurs within a network of social relationships as educators work formally and informally with students (Bajaj, 2013). Some urban schools are fostering conducive learning environments to meet the social-emotional and academic needs of students who live in urban environments while some urban schools are unsuccessful in fostering a conducive learning environment to meet the social emotional and academic needs of students who live in urban settings (Rimm-Kaufman, S. \& Sandilos, L., n.d.) Teacher actions, and interactions, within the learning environment influence the development of student self-esteem and resiliency within students in urban schools.

\section{PURPOSE}

Promoting self-esteem and resilience in students receiving free and appropriate education in urban schools is achievable by identifying teacher actions and aspects of learning environments. Enhancing the professional practices of educators who serve students in urban school settings serve as rationale for researching student experiences contributing to positive mental health. Students graduate from high schools in urban settings with the self-esteem and the resilience needed to matriculate through college and into careers. Some students have not developed self-esteem and resilience, which will create the perseverance necessary to transition and complete college. The National Board for Professional Teaching Standards (1989) indicate teachers should foster and develop student self-esteem. Data from an exploration of behaviors and strategies will aid in developing teacher skills and enhancing professional practice to build student self-esteem and resiliency for academic and social success. 


\section{LITERATURE REVIEW}

Review of the literature for this exploratory study include research defining and connecting student self-esteem, resilience, and mental health. Exploring the goal achievement theory and growth mindset theory as a potential framework for developing teacher strategies to support resilience and self-esteem in students was part of the search strategy. The review also indicates best practices including designing nurturing learning environments as key to fostering resilience.

\section{Mental Health}

The U.S. Department of Health and Human Services (HHS) concluded that mental health is emotional, psychological, and social well-being (n.d.) Disparities identified by the Center for Disease Control (CDC) which may impact adolescent heath include, poverty and educational inequities (n.d.). HHS suggests resilient students cope effectively, despite disparities, when positive student-teacher relationships exist.

Merianos et al. (2013) surveyed college students to study the effect of self-esteem and social support for the students. The purpose of the continuous study includes examination of students' quality of life and universal health. Participants of this study fared better in academics when support was available and offered. The authors' findings indicate selfesteem as a predictor of a student's mental health. The authors maintain commitment to enhancing student's selfesteem is key to academic success.

Crocker and Park (2004) examined the benefits of self-esteem and argues that the pursuit of self-esteem outweighs long-term costs. The findings of Crocker and Parks (2004) research emphasizes the impact on an individual's mental and physical health. The study warns the pursuit of self-esteem may heighten an individual's reaction to a perceived threat. An individual's sense of worth drives the potential conflicting, behavior (Crocker \& Wolfe, 2001).

\section{Resilience}

Definitions of resilience include the capability to face challenges. Consideration of the process of resilience is important in defining resilience (LaFromboise, Hoyt, Oliver, \& Whitbeck, 2006). LaFromboise, et al (2006) suggests youth resilience factors include intrapersonal, interpersonal, and community experiences, while culture impacts all three areas to dictate levels of resilience.

\section{Self-Esteem}

Similar to resilience, Searcy (2007) argues self-esteem is developed through one's associations, ones activity and aurally. Searcy claims these processes result in an individual's overall feelings of self-worth. Identified as associative self-esteem, the term refers to the effect of groups on individual self-esteem. Relationships with peers, family, and teachers influence the development of students' self-esteem.

\section{Urban School Settings}

An understanding of the student experience in urban cities and schools is critical to educators. Peck (2017) covers the emergence of the urban school challenges and explains how the transition of United States cities from industrialized to urbanized communities lead to complex school systems. The end of World War II increased immigrants from the Caribbean and Central America while African Americans moved from the south to northern cities. Peck continues with how Brown vs Board of Education resulted in white flight to the suburbs in resistance to integration. This contributed to the decline of urban cities and schools through poverty and other socioeconomic factors.

Global concerns of the relationship of self-esteem and student academic success include a study of immigrant students' transition into urban school settings and self-segregation (Agirdag, Van Houtee, \& Van Avermaet, 2012). Agirdag et al. (2012) examined student's self-esteem in connection to student segregation in schools. The purpose of the study was to determine if the students' self-segregation occurred because of the relationship between the student and teachers. The authors surveyed students aged 10 to 12 in primary schools in Belgian urban areas. Findings revealed 
some student teacher relationships suppressed student self-esteem. Teachers must understand the impact they have on students and work to build or enhance skills in this area. Findings of the study identifies the relationships between student and teachers, will significantly influence students' self-esteem in some manner.

\section{Grit and Growth Mindset}

Research reveals through the cultivation of growth mindset, educators may motivate students and raise student academic success (Dweck, 2006). Research and development of the growth mindset theory conveys that studying and learning are keys to success and are smart actions teachers can praise to build self-esteem and resilience in students. Growth mindset and achievement goal theory are resources to build a model for supporting positive student mental health and developing self-esteem and resilience in urban school settings.

A trait identified as actions and behavior contributing to perseverance is grit. Researchers in a previous study observed students in a variety of settings to identify individual differences, which predict academic and social success (Duckworth, Peterson, Matthews, \& Kelly, 2007). The guiding research question, "Who is successful here and why?" led to grit, which is defined as perseverance and passion for long-term goals. Grit showed usefulness in forecasting gradual and logical success measures beyond IQ and diligence.

\section{Learning Environments}

The learning environment plays a significant role in the nurture and growth of children (Bajaj, 2013). In a recent, study seventh and eighth graders completed a questionnaire measuring students' personal attitudes regarding the classroom learning environment. The research compared the perceptions of male and female students, as well as the differences in urban and rural learning environments. The students' responses report a learning environment whereas teacher actions include encouragement of self-learning, encouragement of learning by doing and spending extra time with some students.

The physical education learning environment of 700 students in an urban middle school was studied to ascertain the reasons some students eagerly participated while some refused to participate (Blanchfield, 2002). The study examined the impact of the learning environment on student motivation to contribute to class teaching and learning. The results of the study conclude students prefer learning environments whereas teachers support teamwork through cooperative games to competitive games. Teacher actions, which expect and nurture teamwork, enhance student self-esteem.

A recent study of student perceptions of the learning environment in a large urban school district within the United States indicates the environment may not be as teachers intend or as other educators observe (Waxman, Garcia, \& Read 2008). The instrument used to gain student perceptions was the My Class Inventory by B.J. Fraser. The author argues the urban school district has the opportunity to provide positive learning environments and the results of the study indicate this was not occurring. The teaching and learning experience can be enhanced by exploring the students' perception of the learning environment in addition to teacher perceptions.

Students can experience inner conflict in an uncertain learning environment (Akin, 2007). The study of the effect of teacher perceptions of students in the classroom indicates teacher perceptions are transferrable to students and affect student success. Many students who attend urban schools battle the negative perceptions of educators in the classroom. Positive teacher behaviors are crucial for an effective learning environment.

\section{Achievement Goal Theory}

Schultz and Lanehart posit emotions are linked to every component of the student's learning environment (as cited in Partington (2004, p. 5). The authors linked student emotions to the achievement goal theory. In an examination of the achievement goal theory, Zusko and Clayton (2011) address motivation in relation to persistence and the importance of the role of culture in goal achievement. Researchers now question motivation as an individual trait due to disparities of youth in non-typical environments, and suggest individuals use all resources around and available to succeed. The researchers argue the examination will result in supporting further research of the impact of culture on 
motivational processes. Valid motivational processes will support educators' engagement of and relationship with students in the teaching and learning environment.

The connection of student emotions and the learning environment to student learning validates the student and teacher relationship. Defining and understanding the needs of students in urban schools is critical to teacher skills. A review of the literature supports the connection to student achievement, self-esteem, and resiliency. Educators can use these connections to foster resiliency to support student success and offset the disparities students in urban environments may encounter. An inventory of the learning environment will monitor and validate teacher actions, behaviors and best practices for developing student self-esteem and resiliency (Waxman, 2008).

\section{METHODOLOGY}

A qualitative methodology and phenomenological research design was appropriate to explore the perspectives and experiences of high school graduates of an urban learning environment. Graduates' lived experiences of teacher actions in supporting student self-esteem and resilience in an urban learning environment can bring insight to enhance teacher effectiveness. The methodology and design includes interview and survey questions to understand the phenomena and learn from the participants (Creswell, 2005).

An exploration of the development of students' self-esteem and resilience, and how educators can aid in developing the characteristics, was a goal of the research. Realities and lived experiences of participants were important to the phenomenological design (Groenewald, 2004). High school graduates were surveyed to determine the student what happened and what is needed to develop self-esteem and resilience. Factors such as the elements of learning environments, promoting self-esteem and resilience in students in urban schools were examined.

Approximately 20 graduates of high schools in the states of Illinois, and Indiana gave consent to participate, and 14 completed the survey for the study. The respondents answered questions, which included topics of teacher actions which developed or supported resilience or self-esteem. The survey included multiple choice and open-ended questions. Analysis of the data included coding and sorting into a final three categories to share findings.

\section{FINDINGS}

The largest group of participants had careers in education. Participants worked in the healthcare industry, including education of health, and pharmacy. Other fields of occupation include accounting, law enforcement, legal administration, the food industry, and social work.

\section{Learning Environments}

All of the participants agreed the learning environment where the staff population mirrors the student population is idea for fostering resilience and self-esteem. The participants also agreed bringing in speakers and members of the community enhanced the learning environments and supported the students in developing these characteristics.

Table 1. Components of learning environments to foster resilience and self-esteem.

\begin{tabular}{l|c}
\hline \multicolumn{1}{c}{ Suggestions } & Frequency of Response \\
\hline Same gender teacher & 4 \\
\hline Staffed Mirrored Student Culture & 14 \\
\hline Speakers from the community & 13 \\
\hline Learning Out of the classroom & 13 \\
\hline
\end{tabular}

Additional comments included, "When improving students 'self-esteem it has been my experience that specifically instituting cultural achievements/history into the syllabus gives students a sense of pride and confidence. When students of color (inclusive of Black, Latino, and Asian) see, hear, or read truths about their cultural contribution to the American tapestry, the student, almost instantly, displays a sense of pride and confidence." Another comment was, "A learning environment where teachers are trained on culturally responsive teaching practices, embracing 
diversity: student learning, and diverse cultures. The final comment to this question was, "Offering internships and shadowing experiences."

\section{Self-Esteem}

Teacher actions, best supporting the development of student self-esteem, was addressed. The participants wrote the educators required students' best effort and work, used encouragement, verbal praise, positive language, and took the time to develop a rapport and relationship.

Table 2. Teacher behaviors which foster self-esteem in students

\begin{tabular}{l|c}
\hline \multicolumn{1}{c}{ Responses } & Frequency of Response \\
\hline High Expectations & 5 \\
\hline Encouragement & 4 \\
\hline Verbal Praise & 5 \\
\hline Built Relationship & 3 \\
\hline Freedom to Express Myself & 1 \\
\hline
\end{tabular}

\section{Resilience}

The participants' responses to resilience include teacher actions such as building a rapport with students and parents. Discussions about collaborating with parents are key components of the responses to show similar actions and expectations in the classroom and home. Teacher instructional practices included one-on-one conferences, corrective feedback, and addressing all learning styles. Participants' answers indicate teachers held high expectations within the classroom. Fostering high expectations is a teacher action, which demonstrates a belief students can learn.

Table 3. Teacher behaviors which foster resilience in students

\begin{tabular}{l|c|c}
\hline \multicolumn{1}{c|}{ Teacher Actions } & Frequency of Response & Percentage of Responses \\
\hline Personal Conversations and Counseling & 4 & $16 \%$ \\
\hline Partnering with Parents or Community & 4 & $16 \%$ \\
\hline Noticed and Encouraged Skill Development & 5 & $20 \%$ \\
\hline Pushing me to the Next Level & 6 & $24 \%$ \\
\hline Instructional Strategies/Feedback & 6 & $24 \%$ \\
\hline
\end{tabular}

\section{DISCUSSION}

Learning environments, self-esteem, and resilience are among the major factors in the success of students in urban schools (Fallon, 2010). According to the findings of this study, a major factor in helping students establish and develop resilience in urban educational settings include staff who mirrors the student body. One hundred percent of the graduates believed similar staff is a positive factor, contributing to the development of positive self-esteem in students. The findings of this research may contribute to school administrator criteria for establishing hiring and recruitment practices.

Results of the study reveal speakers from the community and educators who form relationships with students outside of the classroom setting is important to students in urban school settings. Nighty-two percent of the participants shared listening to speakers in the community and developing relationships beyond the classroom with educators is a determining factor in feeling supported and establishing student's self-esteem. Only $28 \%$ of the graduates felt a samegender educator, (male student preferring male teacher, and female student preferring female teacher) was an important factor in helping students feel supported in building self-esteem.

While all of the factors mentioned have an impact on developing resiliency and building self-esteem in students, the teacher actions the participating graduates highlight in this study, indicate educators should design learning activities for academic and socioemotional support in urban learning environments. A few participants did indicate the teachers did nothing to develop resilience. 


\section{IMPLICATION TO LEADERSHIP}

Resilience and self-esteems are key factors to student success and can be impacted by teacher actions and behaviors. School leaders can use data to develop a model for initiating awareness and implementing procedures to foster resilience and self-esteem. Prior to school leaders deciding on a model for resilience or self-esteem in urban school settings gaining buy-in will be important to successful implementation. Determining factors for successful application of a new school model depends upon how well the school leader prepares stakeholders to embrace the cultural shift (Radford, 2014). A collaborative culture will enhance buy-in to support student long-term success.

\section{CONCLUSION}

The academic and professional success of some students is the result of students' social emotional progress and mental health (Merianos, et al.,2013). Students who live in urban environments benefit from educators who offer social emotional support as well as academic support. The learning environment and teacher actions influence students' short-term and long-term success. The data and information within this study highlights the student and teacher relationship experiences in urban learning environments, which can help determine future success in students who live and learn in urban settings.

\section{AUTHOR BIOGRAPHIES}

Dr. Imani Akin earned a MS in Special Education in 2005 and an EDD in Education Administration. She has taught in elementary and high schools and served as a high school case manager and department head of special education. She is a special education content instructor for the University of Phoenix.

Dr. Radford served as director of college and careers in a high school and currently teaches for the University of Phoenix.

\section{REFERENCES}

Agirdag, O. Van Houtee, M. \& Van Avermaet, P. (2012). Ethnic school segregation and self-esteem: The role of teacher-pupil relationships. Urban Education, 47. doi:10.1177/004208591245

Ahram, R., Stembridge, A., Fergus, E. \& Noguera, P. (n.d.). Framing urban school challenges: The problems to examine when implementing response to intervention. RTI Action Network. Retrieved from http://www.rtinetwork.org/learn/diversity/urban-school-challenges2154

Akin, I. (2007). The effect of teacher perception on student placement in restrictive environments: A grounded theory study. (Order No. 3292151, University of Phoenix). ProQuest Dissertations and Theses, 192. Retrieved from http://search.proquest.com/docview/304732423? accountid=458. (304732423).

Bajaj, S. (2013). Study of learning environment of urban and rural government middle schools: An overview of Jammu district. Asian Journal of Research in Social Sciences and Humanities, 3(2), 273-280. Retrieved from https://aijsh.com/

Blanchfield, J. L. (2002). The influence of learning environments on intrinsic motivation in urban middle school physical education students. (Order No. 1412788, California State University, Fresno). ProQuest Dissertations and Theses, 63. Retrieved from http://search.proquest.com/docview/250156112? accountid=458. (250156112).

Center for Disease Control and Intervention. (n.d.). Health disparities. Adolescent and School Health. Retrieved from https://www.cdc.gov/healthyyouth/disparities/index.htm

Creswell, J. W. (2005). Educational research: Planning, conducting, and evaluating, quantitative and qualitative research. Upper Saddle, NJ: Pearson, Merrill, Prentice Hall

Crocker, J., \& Park, L. E. (2004). The costly pursuit of self-esteem. Psychological Bulletin, 130(3), 392-414. doi:10.1.1.336.8676\&rep=rep1\&type=pdf

Crocker, J., \& Wolfe, C. T. (2001). Contingencies of self-worth. Psychological Review, 108(3), 593-623. http://dx.doi.org/10.1037/0033-295X.108.3.593

Duckworth, A. L., Peterson, C., Matthews, M. D., \& Kelly, D. R. (2007). Grit: Perseverance and passion for long-term goals. Journal of Personality and Social Psychology, 92(6), 1087-1101. doi:http://dx.doi.org/10.1037/0022-3514.92.6.1087

Dweck, C. S. (2006). Mindset: The new psychology of success. Ballantine Books, 12. Retrieved from http://insight.randomhouse.com

Fallon, C. M. (2010). School factors that promote academic resilience in urban Latino high school students. Loyola eCommons. Retrieved from http://ecommons.luc.edu/cgi/viewcontent.cgi?article=1121\&context=luc_diss 
Groenewald, T. (2004). A phenomenal research design illustrated. International Journal of Qualitative Methods, 3(1), Article 4. Retrieved from https://journals.library.ualberta.ca/ijqm/index.php/IJQM

LaFromboise, T. D., Hoyt, D. R., Oliver, L., \& Whitbeck, L. B. (2006). Family, community, and school influences on resilience among American Indian adolescents in the upper Midwest. Journal of Community Psychology, 34(2), 193-209. doi: $10.1002 /$ jcop. 20090

Merianos, A. L., Nabors, L. A., Vidourek, R. A., King, K. A. (2013). The impact of self-esteem and social support on college students' mental health. American Journal of Health Studies, 28(1), 27. http://www.va-ajhs.com/ https://www.thefreelibrary.com/The+impact+of+self-esteem+and+social+support+on+college+students\% $27 \ldots$.. a0347969670

National Board for Professional Teaching Standards. (1989). What teachers should know and be able to do. Five Core Propositions. Retrieved from http://www.nbpts.org/five-core-propositions

Partington, K. (2004). The impact of self-esteem on academic achievement and aspirations of urban minority adolescents. UMI ProQuest Digital Dissertations.

Peck, C. (2017). Urban school reform in the United States. Education and Society. doi:10.1093/acrefore/9780190264093.013.27view/305092999?accountid=458. (305092999).

Radford, L. (2014). Proceedings of Hawaii International Conference on Education: Changing school models: Maintaining school culture. ISSN 1541-5880, 01/2014, 12, pp. 2457-2470 Retrieved from http://www.hiceducation.org/EDU2014.pdf

Rimm-Kaufman, S. \& Sandilos, L. (n. d.). Improving students' relationships with teachers to provide essential supports for learning: Positive relationships can also help a student develop socially. American Psychological Association. Retrieved from http://www.apa.org/education/k12/relationships.aspx?item=1

Searcy, Y. (2007). Placing the horse in front of the wagon: Toward a conceptual understanding of the development of selfEsteem in children and adolescents. Child \& Adolescent Social Work Journal, 24(2), 121-131. doi:10.1007/s10560006-0070-9

U.S. Department of Health \& Human Services. (n.d.). What is mental health? Retrieved from https://www.mentalhealth.gov/basics/what-is-mental-health/index.html

Waxman, H. C., Garcia, A., \& Read, L. L. (2008). Classroom learning environment and student motivational differences between exemplary, recognized and acceptable urban middle level school. Middle Grades Research Journal, 3(2), 121. Retrieved from eric.ed.gov

Zusko, A., Clayton, K. (2011). Culturalizing achievement goal theory and research. Educational Psychologist, 46(4), 239-260. http://dx.doi.org/10.1080/00461520.2011.614526 


\section{NOTES}

